\title{
(息)
}

Citation:

Ashford, M and Abraham, A and Poolton, J (2020) A Communal Language for Decision Making in Team Invasion Sports. International Sport Coaching Journal. pp. 1-8. ISSN 2328-918X DOI: https://doi.org/10.1123/iscj.2019-0062

Link to Leeds Beckett Repository record:

http://eprints.leedsbeckett.ac.uk/6783/

Document Version:

Article

The aim of the Leeds Beckett Repository is to provide open access to our research, as required by funder policies and permitted by publishers and copyright law.

The Leeds Beckett repository holds a wide range of publications, each of which has been checked for copyright and the relevant embargo period has been applied by the Research Services team.

We operate on a standard take-down policy. If you are the author or publisher of an output and you would like it removed from the repository, please contact us and we will investigate on a case-by-case basis.

Each thesis in the repository has been cleared where necessary by the author for third party copyright. If you would like a thesis to be removed from the repository or believe there is an issue with copyright, please contact us on openaccess@leedsbeckett.ac.uk and we will investigate on a case-by-case basis. 


\section{A Communal Language for Decision-Making in Team Invasion Sports}

Ashford, M., Abraham, A.K. \& Poolton, J.***

*** Research Centre for Sport Coaching, Carnegie School of Sport, Leeds Beckett University.

M.Ashford@leedsbeckett.ac.uk

http://dx.doi.org/10.1123/iscj.2019-0062

Ashford, Michael., Abraham, Andrew., \& Poolton, Jamie., (null). "A Communal Language for Decision Making in Team Invasion Sports". International Sport Coaching Journal. Advance online publication. https://doi.org/10.1123/iscj.2019-0062. 


\begin{abstract}
Invasion team sports coaches are faced with the problem of developing players that in any given situation can make decisions that lead to successful outcomes. Research into human decision-making has established three widely accepted perspectives, which sports coaching has used to understand player decision-making and inform practice; information processing, ecological psychology and naturalistic decision-making. As a result, coaches are challenged with perspective-specific terminology and having to draw connections amongst similar findings that are explained in quite different ways. This conceptual paper presents a plainer account of player decision-making by proposing a communal language within a conceptual framework for decision-making in invasion team sports. It is hoped that the proposed language and framework will together facilitate knowledge exchange between researchers and coaches for the betterment of player development.
\end{abstract}

\title{
Keywords
}

Information processing, ecological psychology, naturalistic decision-making, perception, information, knowledge. 


\section{Introduction}

A necessary challenge for coaches of invasion team sports is to develop players that in any given situation select the option that will most likely progress the team towards their overarching aim - 'to score more points/goals than their opponent' (Richards, Collins, \& Mascarenhas, 2012, 2017). The importance of player decision-making is highlighted by the volume of research dedicated to better understanding it (Araújo et al., 2019; Raab \& Araújo, 2019; Toner, Montero, \& Moran, 2015; Williams \& Jackson, 2019). Despite the rigour and impact of this empirical work there is no single view on how players make decisions (Araújo et al., 2019; Raab \& Araújo, 2019; A. M. Williams \& Jackson, 2019) instead, three, supposedly distinct, research perspectives have emerged; information processing, ecological psychology and naturalistic decision-making.

Often researchers are deeply rooted in one philosophical camp that interpretation of empirical data presents just one side of the argument (this is nicely illustrated by recent review articles, (Araújo et al., 2019; Raab et al., 2019; Williams \& Jackson, 2019). As a result, the well-intended coach is forced to first understand and then draw connections among findings that are explained in quite different ways. The challenge is heightened by the establishment of perspective-specific lexicon, which offers different terms for similar concepts, and is compounded by the sharing of ideas via social media, which can result in nuanced misinterpretations of empirical evidence and perspectives (MacNamara \& Collins, 2015). Thus, a coach's engagement with research can lead to bewilderment, conceptual blind spots and convoluted solutions to an intricate practical problem. To deliver some clarity, this paper aims to provide a plainer account of decision-making in invasion team sports by adopting a neutral stance. We do not intend to be critical, address methodological concerns or suggest that a certain perspective holds more weight than another. Instead, we take a mediating position to develop a communal language that is housed by a unified conceptual 
framework for team player decision-making. In doing so, we hope this paper provides an aide memoire to make potentially valuable research more accessible to coaches.

\section{Three research perspectives on player decision-making}

The crux of the difference between the three perspectives is the role of cognition in decision making (Raab \& Araújo, 2019). From an information processing perspective, certain competitive situations demand a conscious interaction with task specific information to avoid performance errors (Toner et al., 2015; Toner \& Moran, 2015):

experts must be able to deliberately access and strategically re-route any semiautomated routines in order to facilitate "continuous improvement" (Montero, 2010; Breivik, 2013). (Toner \& Moran, 2015; p2)

In contrast, the ecological dynamics perspective proposes that decisions are made through an automated process where perception and action are coupled through the information available in the environment (Gibbs, 2006; Araújo, Davids, \& Hristovski, 2006):

This theoretical rationale proposes that the most relevant informational constraints for decision-making and controlling action in dynamic environments such as a rugby match are those that emerge during on-going performer-environment interactions, not information from past experiences stored in the brain. (Passos et al., 2008; p. 131)

Since each perspective disputes the way decisions are processed, at this point it is pertinent to clarify each view. Those schooled in information processing tend to present decision making as a conscious process of selection, in which expert players excel in their capability to extract and process cues from the environment (Müller, Abernethy, \& Farrow, 2006), recognise and interpret familiar patterns of play (Lorains, Ball, \& MacMahon, 2013; Tenenbaum \& Summers, 1997; A Mark Williams \& Ward, 2007) and form expectations by computing situational probability (Abernethy et al., 2001; Farrow \& 
Reid, 2012; Loffing \& Hagemann, 2014). This process of selection is viewed as a conscious agent between what a player perceives (perception) and how a player responds (action) to the play unfolding about them (Johnstone \& Morrison, 2016; Macquet, 2009; Macquet \& Kragba, 2015). For example, a centre in netball receives the ball with two options to pass forwards to the goal attack or the goal shooter. The centre processes the cues available, which indicate that the goal shooter is being well marked by the goalkeeper, whereas the goal attack has lost their defender and is free in open space. As such the familiarity associated with this situation leads the player to the judgment that the risk is too high to pass to the goal shooter and instead decides to pass to the goal attack.

In contrast, the school of ecological dynamics describes how behaviour emerges because of an ongoing reciprocal relationship between perception of information, which constrains movement, and action, which creates information (Greenwood, Davids \& Renshaw, 2016; Kelso, 1995; Warren, 2006; Williams \& Davids, 1998). The coupling of perception and action can be captured as opportunities for action (or options), known as affordances (Fajen, Riley, \& Turvey, 2008; or perceiver effectivities within action-specific perception theory, Witt \& Riley, $2014^{1}$ ), which are defined relative to the task goal, structure of the environment and the action capabilities of the performer. For example, a rugby player would only perceive the affordance to run through a gap between defenders if they had the requisite physical stature and speed to do so (Fajen et al., 2008; Gibson, 1979). Fajen et al's idea of affordances (2008) was extended to explain how individuals within a team coordinate their behaviours (Silva et al., 2013). The concept of shared affordances describes a collective perception of what is possible within the constraints of a context (Silva et al., 2013). For example, a rugby player is only afforded the opportunity to chip the ball into space beyond the defence if their teammate

\footnotetext{
${ }^{1}$ Witt \& Riley's (2014) review paper attempts to reconcile the ecological approach with action-specific perception theory.
} 
is perceived to be able to outrun the defenders and evade the onrushing fullback. Therefore, the kicker must factor in the perceived action capabilities of a range of external agents (i.e., the receiver, the defenders and the fullback), whist the receiver must perceive the technical capability of her teammate to execute the kick and 'read' the situation.

An intermediary view, naturalistic decision-making, (Zsambok \& Klein, 1996; Klein, Calderwood, \& Clinton-Cirocco, 2010) argues that in highly pressurised, time constrained situations decisions are made through a recognition primed process (RPD) where a person's interaction with information varies from automated to conscious depending on the decision maker's familiarity with the situation (visual, auditory, olfactory etc.) and their requisite knowledge base (Klein et al., 1986; Klein et al., 2010). The decision-making process is formed of three levels; i) simple match, ii) diagnose the situation and iii) evaluate a course of action (Klein et al., 1986, 2010). Simple match represents a case in which a player perceives the situation as typical, as the information that is available to the player matches their initial expectations of the situation, leading to an automated decision response. Diagnose the situation represents a case where the information available is not typical (Zsambok \& Klein, 1996). The decision maker must clarify the goals, cues and expectations of the situation through a process of diagnosis to restore typicality and arrive at a decision (Zsambok \& Klein, 1997). Evaluate a course of action represents a more complex scenario where the information available (goals, cues and expectations) demands a deliberate assessment of possible options and the difficulties that may emerge in taking each approach. To do this, the decision maker runs mental simulations to test, disregard and select an appropriate course of action.

The only distinct difference between each perspective centres on the presence of memory representations to facilitate the selection of a course of action. Recently, Raab and Araujo (2019) explored the presence of memory within the decision-making process through the lens of the information processing (Raab) and ecological psychology (Araujo) perspective. 
They concluded that no 'single' theoretical perspective captures player decision-making in its entirety. Instead, they proposed that the presence of memory representations is dependent on the lens one looks through. Such a verdict suggests that a framework to facilitate the assimilation of knowledge borne from each perspective would help progress collective understanding of player decision-making in invasion team sports (e.g., Ribeiro et al., 2019; Bourbousson, Feigian \& Seiler, 2019; Hoffman et al., 2013). We next present an attempt to construct a unified framework that encompasses a communal language for decision-making in team sports.

\section{A unified conceptual framework for player decision-making in invasion team sports}

Decision-making in invasion team sports can be compartmentalised into three facets: the game; the player; and the coach. The facets are not mutually exclusive, as each interacts with the other (Richards, Collins \& Mascerenhas, 2017; Passos et al., 2008). The game sits at the centre of the framework presented in Figure 1, as the goal and rules of the game interact to create problems that both the player and the coach need to solve. The player interacts directly with both the game and the coach. The player serves as the coach's agent by acting out shared solutions to the problems the game presents. Each of the three research perspectives contribute to our understanding of how the game, the player and the coach interact. It is our view that the knowledge generated can be unified and expressed as a communal language for decision-making in invasion team sports. 


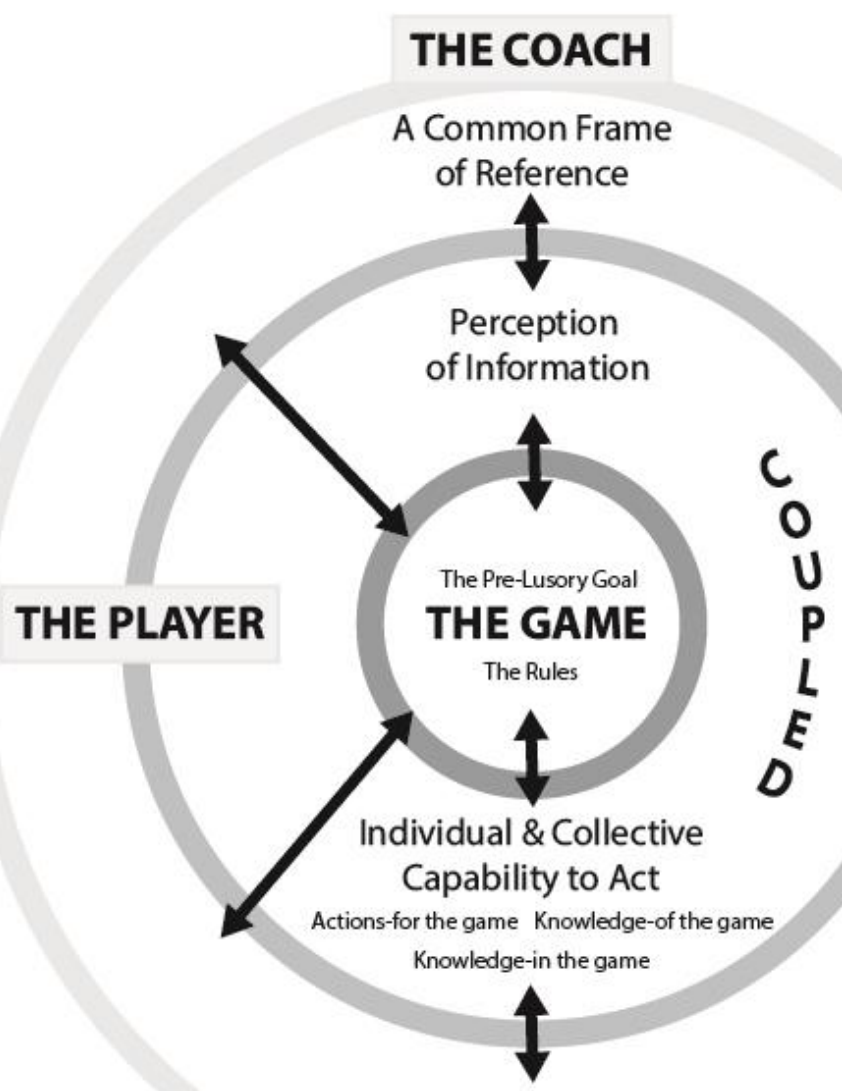

Develop Player Capabilities

Figure 1: A unified conceptual framework for player decision-making in invasion team sports

\section{A Communal Language for Decision-Making in Invasion Team Sports}

\section{The Game}

Invasion games present an 'uncertain' performance environment, however, the options available to a player are directly governed by two overarching concepts, the pre-lusory goal and the rules of the game (Suits, 1978). The pre-lusory goal describes the overarching aim of a sport, which in the case of an invasion game is 'to score more points/goals than your opponent'. The rules prohibit a team from winning through more efficient means - that is, 
cheating (Grehaigne, Godbout, \& Bouthier, 1999) - by specifying the area of play and acceptable actions within it. The interaction between a sport's pre-lusory goal and the rules shape the internal logic of a game (Grehaigne et al., 1999; Suits, 1978) and the game-specific information that players must act upon. Continual interaction with the rules allows players to refine their suite of options for a specific moment in the game (Silva et al., 2013).

\section{The Player}

\section{Perception of Information}

Advocates of ecological dynamics suggest that perception is 'of affordances' which are the invitations for action specified by the game rules and the actions of those around the decision-maker, e.g. a gap to run through (Araújo et al., 2019). The information processing perspective suggests that skilled players better identify information through salient (McPherson \& Vickers, 2004), predictive (McRobert et al., 2011), global cues (Johnston \& Morrison, 2016) within the context of their intended goal. Whilst, naturalistic decision-making argues that patterns of a typical and familiar nature are recognised through the perception of relevant information:

The RPD model suggests that people can assess the given situation by recognizing its typicality. The decision maker recognizes the situation through salient features that experience has shown to be useful. Recognition has four by-products: (a) expectancies,

(b) relevant cues, (c) plausible goals, and (d) typical action. (Macquet, 2009; p. 66)

Therefore, each perspective similarly expresses the notion that the perception of information actuates the decision-making process (Correia et al., 2012; Johnston \& Morrison, 2016; Macquet, 2009; McRobert et al., 2011; Poplu et al., 2008).

Further exploration of perception of information reveals that it is task dependent, that is, player's visual fixations and verbal descriptions change in line with changes in the demands of the task, presumably as they search for means to a successful outcome (Roca et al., 2011; 
Roca et al., 2013; Roca, Williams, \& Ford, 2012). Moreover, expert players develop an improved connection to the information the performance environment offers over time (Abernethy, Zawi, \& Jackson, 2008; Araújo et al., 2019; Esteves et al., 2012; Williams \& Jackson, 2019). For instance, Jackson, Warren and Abernethy (2006) found that skilled rugby players can see through the deceptive acts of their opponents:

skilled players are better able to detect and respond appropriately to advance deceptive visual information, highlighting an additional characteristic of anticipation skill. (Jackson, Warren \& Abernethy, 2006; p. 368)

Finally, conditioning of skilled players to information that best leads to successful outcomes is more commonly known in ecological psychology as perceptual attunement (Esteves et al., 2012). In total therefore, terms that capture the perceptual element of goal-based decision-making, such as perceptual attunement, familiarity, typicality, affordances and cues of a salient, global, relevant, anticipatory or deceptive nature - adopted by each perspective can be much more simply termed the perception of information ${ }^{2}$.

\section{Individual and collective capability to act}

Ecological psychology argues that players have an inherent perception of what is technically and physically possible (action capabilities) in the context of the intended goal (Cordovil et al., 2009). Empirical data supports the idea that a player's physical (e.g., speed) (Passos et al., 2012a) and technical (Paterson et al., 2013) attributes directly influence the action taken. In turn, the information a player perceives cannot be separated from the capabilities they possess, as their capabilities are what guide them to the information to perceive in the first instance (Davids, 2008). For example, a rugby player who is strong,

${ }^{2}$ Perception is not only of visual information, but also refers to the information a player can hear (acoustic) and feel (haptic). 
powerful and fast with the ball in hand is likely to perceive more gaps to run through than a slower, less powerful player. However, it is important to note that players, and perhaps coaches, tend to overestimate their capabilities which can lead to mistakes (when overestimating) or passive play (when underestimating). The implication for the coach in this example would be to develop appropriate capabilities for the demands of the game e.g. speed, power, strength and technical proficiency (Wilson et al., 2019). By doing this a coach would develop the players actions-for the game.

Alternatively, the information processing view would suggest a player's capability to act is moulded from a richer pool of task specific declarative knowledge (Afonso et al., 2012; Evans et al., 2012; Lex et al., 2015; McPherson \& Vickers, 2004; Roca et al., 2011; Roca et al., 2013) stored as mental representations (Afonso et al., 2012; McPherson \& Vickers, 2004; McRobert et al., 2011). It is presumed that mental representations afford the rapid selection of suitable action plan profiles that allow experts to effectively operate in dynamic game environments (Evans et al., 2012). For instance, Johnstone and Morrison (2016) found that expert rugby league players were capable to verbally report the reason why they acted the way they did; "I can't see the fullback so the kick would be an option" (Johnstone \& Morrison, 2016; p. 404). Players who have a deeper knowledge of their sport possess the capability to understand why an action would be more appropriate in one situation than another (Johnston \& Morrison, 2016; McPherson \& Vickers, 2004; Poplu et al., 2008) and they are therefore, maybe, more likely to explore the boundaries of their action capabilities. Considering this, a player's knowledge-of the game increases their capability to act.

Naturalistic decision-making argues that a player's use of knowledge and memory is dependent on their recognition of a situation (Klein et al., 2010; Macquet, 2009; Macquet \& Kragba, 2015). Jackson et al (2006) conclude that skilled players use heuristic-based judgments when the perceptual information is highly typical. Heuristics become established by the 
repetition of an action in response to information that proves to be successful over time (Kahneman et al., 1982). For example, a basketball player forms a heuristic about how to get through a defender's screen, preferring to go over the top rather than below, leading to preference towards a flare cut response. Yet, as players recognise less typicality in a situation, they are required to make sense of the information as their heuristic-based-judgements would no longer lead to a satisfactory action (Macquet \& Kragba, 2015).

The idea of making sense implies that a player is recurrently perceiving information in consultation with their knowledge of the game (Macquet \& Kragba, 2015). Yet, if new information arises, such as an opposing player showing unexpected (or atypical) behaviour, their situation-specific knowledge would need to be updated in game (McPherson \& Vickers, 2004). Ecological psychologists would describe this as perceptual calibration between context-specific information and actions for the game, resulting in a more refined capability to act to the given situation (Araújo et al., 2019; Esteves et al., 2012). Information processors would describe this as a current event profile where a player frequently updates competitive information within their memory during performance (e.g. an opponent's strengths) (MacMahon \& McPherson, 2009; McPherson \& Vickers, 2004). Whether its players making sense, calibrating, or using a current event profile, players are not only required to have knowledge-of the game but are also required to update their knowledge-in the game in order to adapt to sudden changes to the perception of information.

In sum, a player's actions-for, knowledge-of and knowledge-in the game shape their individual and collective capability to act. However, capability to act is inherently dependent on the interaction of the player with perceptual information born out of the game. Consequently, the perception of information is always coupled with a player's and teams individual and collective capability to act.

\section{The Coach}




\section{A common frame of reference}

Invasion games require players to mutually coordinate their perception of information and their individual and collective capability to act (Steiner, Macquet, \& Seiler, 2017). This concept has been captured by shared mental models (Richards, Collins, \& Mascarenhas, 2012; Richards, Collins, \& Mascarenhas, 2017) and shared affordances (Passos et al., 2012; Silva et al., 2013). Richards and colleagues (Richards et al., 2012, 2017) argued that a shared mental model:

enables players and teams to attend to information that is significant in the display, prioritise and then order this information so that the correct course of action can be determined. (Richards, Collins \& Mascarenhas, 2012; p. 409)

A shared mental model is typically developed by the coach as an ideal vision of what performance would look like before being impressed on the coaching staff and players to create a mutual shared view (mental representation) of success. A critical by-product of a shared mental model is the development of a common language, which supports the agreed perception of roles, responsibilities and success (Richards et al., 2012). For example, a defender within rugby union may signal that the attacking team have an overlap using a word that stimulates a coordinated action from the team.

Ecological psychology contends that coordination of behaviour relies on a collective perception of information (Duarte et al., 2012a; Duarte et al., 2012b; Passos et al., 2008), "by perceiving and using affordances for and affordances of others, players can share affordances, and this helps to explain how teammates are able to control their actions in a coordinated way." (Silva et al., 2013; pp. 768-769). For example, a supporting basketball player perceives that a defender is blocking their teammates route to the basket. The player in possession of the ball also perceives this information. In a coordinated act the supporting player uses their body to screen the defender, leaving a gap for the teammate to dribble towards the basket (Ruano et al., 2015). Regardless of differences in terminology and underlying ontological views, shared 
mental models and shared affordances both suggest that by establishing a common frame of reference coaches can affect their players' perception of information and their individual and collective capability to act.

\section{Develop player capabilities}

It is the role and responsibility of coaches to work with players to develop their capacity to solve tactical problems within competitive situations. From an ecological psychology perspective, coaches who seek to develop their players perception of information and actionsfor the game should acknowledge the non-linear nature of learning; that is, accept that a player's rate of progression towards a criterion is not predictable (Chow, 2013; Chow, Davids \& Button, 2015). Advocates of non-linear pedagogy argue that learning environments should be designed to mirror real game contexts (Chow, 2013; Passos et al, 2008; Dicks et al, 2009). The principle of representativeness compels players to interact directly with game-specific information. It is claimed that this appropriately educates players' perception of information (Fajen, Riley \& Turvey, 2008) and positively influences the development of both technical (Travassos et al, 2012) and physical capability (Esteves, de Oliveira \& Araujo, 2011; Wilson et al, 2018). Crucially, contextualised learning activities must contain the functional perception-action relationships (coupling) that coaches want their learners to discover, so that players learn to recognise the personal (Fajen, Riley \& Turvey, 2008) and shared (Silva et al, 2013) affordances offered by the game. Therefore, from an ecological psychology perspective, the role of the coach is to design practice activities that facilitate the search for tactical and technical solutions to real-game problems (Chow, 2013). This is done by the purposeful manipulation of constraints, such as practice space, rules, equipment and players (Chow et al, 2013; 2006; 2007).

From the information processing and naturalistic decision-making perspective, the development of player capabilities centres on knowledge-of the game (McPherson \& Vickers, 
2004). Macquet and Kragba (2015) suggest that this rests on players developing a shared understanding of why certain decisions are more appropriate in specific situations than others, which allows players to evaluate and make sense of the information available; that is, develop a common frame of reference or playbook (Macquet \& Kragba, 2015; Richards, Collins \& Mascarenhas, 2012). Richards and colleagues (2009; 2012; 2017) recommend coaches use slow deliberate environments (off-field) to build knowledge-of the game. Off-field environments should encourage players to reflect-on-action, in order to strategise and plan for the perception of information and the appropriate action in response to it (Richards et al, 2009; 2012; 2017). Reflection-on-action can be stimulated by video and notational analysis, which allow players to see the moment of the game from an external point of view and review information that was available but perhaps not perceived in-action (Richards, Collins \& Mascerenhas, 2017).

The variable nature of invasion team sports necessitates the development of players capability to adapt to perturbations to perceptual information. Richards and her colleagues (2017) argue that the development of knowledge-in the game requires the design of applied knowledge (on field) environments that encourage players to reflect-in-action. The practice should draw the attention of players toward the perception of information, whilst other players and the coach provide specific feedback.

Simon (1965) suggested that decision-making may best be understood by considering the context in which the decision is made. Bar-Eli, Plessner and Raab (2011) argue that when the perception of information is complex - higher number of options and more time - it is better to plan intentional decision-making training (explicit learning) environments, such as the use of coach-led if-then rules of thumb (heuristics; McPherson et al., 1999; 2004). That is, players should be encouraged to explicitly connect their perception of information to their knowledgeof the game. In contrast, incidental decision-making training (implicit learning) was deemed to be more appropriate when the perception of information is simpler - fewer options and less 
time (Bar-Eli, Plessner \& Raab, 2011). Incidental decision-making training conforms to the design principles advocated by non-linear pedagogy (Chow, 2013) in that practice provides frequent exposure to the perception of information in order to identify invariances between the information perceived and the action planned (Bar-Eli, Plessner \& Raab, 2001).

\section{Implications for the use of the unified framework for researchers and practitioners}

Karl Popper (1968) argued that the purpose of research is the search for truth and that truth can never be proven, but research can contribute knowledge that can be applied to make sense of a problem (Veronesi, 2014). The aim of this paper was to create a communal language for decision-making in invasion games that assists the acquisition and application of knowledge. To this end, a unified conceptual framework is presented that, independent of viewpoint, encapsulates player decision-making process in invasion team sports. Table 1 provides a glossary of perspective-specific terminology aligned to the communal language developed within this paper. It is our hope that the table can provide an aide memoire for coaches and researchers to better facilitate the exchange of knowledge.

From a research perspective, future investigations should focus on the specific interactions between the game, the player and the coach. Research into the interaction between the game and the player could consider how players adapt their decision-making following rule/law changes, both behaviourally (e.g. tackles, carries, rucks, ball in play time; Van den Gerg \& Malan, 2012) and cognitively. Likewise, the rule/law change to the game might have implications for the coach, such as the revision to the common frame of reference they impose on their team (Richards et al., 2017). Furthermore, the work of Raab (2003) and Bar Eli, Plessner \& Raab (2011) could be extended by exploring the impact on the player of moments in the game that vary in complexity and the time to decide. Finally, research should study how the demands of the game are perceived and captured by the coach and impressed onto players. 
Does the thinking and doing of coaches align to the theory and practice principles offered by researchers?

From a practical perspective, high-level coaches can struggle to bring coherence to their thoughts (Abraham, Collins and Martindale, 2006), whereas, serial winning coaches are excellent at creating a vision of what performance should look like (Lara-Bercial \& Mallett, 2016). Reference to the unified framework might help coaches across performance levels achieve clarity of thought on both the process of player decision-making and what, specifically, the coach can affect (Richards et al., 2009; 2012; 2017). The coach can then use their practice informed knowledge to design learning environments to accelerate the development of specific individual and collective capabilities to act and to educate the perception of information. It may be found that the balance and blend of intentional (explicit) and incidental (implicit) decision making training activities used are inextricably linked to the context within which the decision is made in competition (Raab, 2003; Bar-Eli, Plessner \& Raab, 2011). Moreover, it is hoped that reference to the unified framework makes valuable research accessible to coaches; bolstering both their own professional development and the decision-making of the players in their charge. 
Table 1: A communal language for player decision-making in invasion team sports (quotation marks denote the communal language terminology)

\begin{tabular}{|c|c|c|c|c|c|c|c|}
\hline The Game & & & e Player & & & & The Coach \\
\hline \multirow{16}{*}{$\begin{array}{l}\text { The pre- } \\
\text { lusory goal } \\
\text { \& } \\
\text { The rules }\end{array}$} & \multirow{2}{*}{ Perspective } & \multirow{2}{*}{$\begin{array}{l}\text { "Perception of } \\
\text { information" }\end{array}$} & \multicolumn{3}{|c|}{ "Individual \& collective capability to act" } & \multirow{2}{*}{$\begin{array}{l}\text { "A common frame } \\
\text { of reference" }\end{array}$} & \multirow{2}{*}{ "Develop player capabilities" } \\
\hline & & & "Actions-for the game" & "Knowledge-of the game" & "Knowledge-in the game" & & \\
\hline & \multirow{4}{*}{$\begin{array}{l}\text { Information } \\
\text { processing }\end{array}$} & Salient cues & & Mental Representations & & \multirow{2}{*}{ Shared mental model } & Intentional decision-making training (explicit) \\
\hline & & Global cues & & Declarative knowledge & & & Incidental decision-making training (implicit) \\
\hline & & Predictive cues & & Long term working memory & & \multirow{2}{*}{ Common language } & \multirow[b]{2}{*}{ Planning \& strategising } \\
\hline & & Anticipatory cues & & Action plan profile & & & \\
\hline & \multirow{5}{*}{$\begin{array}{l}\text { Naturalistic } \\
\text { decision- } \\
\text { making }\end{array}$} & Pattern recognition & & \multirow{5}{*}{ Evaluation } & Current event profile & \multirow{2}{*}{ Shared mental model } & \multirow{2}{*}{ Slow deliberate environment (off field) } \\
\hline & & Relevant cues & & & Heuristics & & \\
\hline & & Typicality & & & & \multirow{3}{*}{ Common language } & \multirow{3}{*}{ Applied knowledge environment (on field) } \\
\hline & & \multirow{2}{*}{ Familiarity } & & & & & \\
\hline & & & & & Procedural knowledge & & \\
\hline & \multirow{5}{*}{$\begin{array}{l}\text { Ecological } \\
\text { Psychology }\end{array}$} & Affordances & Action capabilities & & \multirow{5}{*}{ Perceptual calibration } & \multirow{3}{*}{ Shared affordances } & \multirow{2}{*}{ Non-linear pedagogy } \\
\hline & & \multirow{2}{*}{ Shared affordances } & \multirow{2}{*}{ Physical } & & & & \\
\hline & & & & & & & Representativeness \\
\hline & & \multirow{2}{*}{$\begin{array}{l}\text { Perceptual } \\
\text { attunement }\end{array}$} & \multirow{2}{*}{ Technical } & & & \multirow{2}{*}{ Intention } & Manipulation of constraints \\
\hline & & & & & & & Perception-action coupling \\
\hline
\end{tabular}




\section{References}

Abernethy, B., Gill, D. P., Parks, S. L., \& Packer, S. T. (2001). Expertise and the perception of kinematic and situational probability information. 30(2), 233-252. doi:10.1068/p2872

Abernethy, B., Zawi, K., \& Jackson, R. C. (2008). Expertise and attunement to kinematic constraints. Perception, 37(6), 931-948. doi:10.1068/p5340

Abraham, A., Collins, D., \& Martindale, R. (2006). The coaching schematic: Validation through expert coach consensus. Journal of Sports Sciences, 24, 549-564. doi:10.1080/02640410500189173

Afonso, Garganta, J., McRobert, A., Williams, A. M., \& Mesquita, I. (2012). The perceptual cognitive processes underpinning skilled performance in volleyball: Evidence from eye-movements and verbal reports of thinking involving an in situ representative task. Journal of Sports Science and Medicine, 11(2), 339-345.

Araújo, D., Davids, K., \& Hristovski, R. (2006). The ecological dynamics of decision making in sport. Psychology of Sport and Exercise, 7(6), 653-676. doi:https://doi.org/10.1016/j.psychsport.2006.07.002

Araújo, D., Hristovski, R., Seifert, L., Carvalho, J., \& Davids, K. (2019). Ecological cognition: Expert decision-making behaviour in sport. International Review of Sport and Exercise Psychology, 12(1), 1-25. doi:10.1080/1750984X.2017.1349826

Bar-Eli, M., Plessner, H., \& Raab, M. (2011). Judgment, decision-making and success in sport. Malden, MA: Wiley.

Bourbousson, J., Feigean, M., \& Seiler, R. (2019). Team cognition in sport: How current insights into how teamwork is achieved in naturalistic settings can lead to simulation studies. Frontiers in Psychology, 10, 2082-2082. doi:10.3389/fpsyg.2019.02082 
Chow, J. Y., Davids, K., Button, C., Shuttleworth, R., Renshaw, I., \& Araújo, D. (2007). The role of nonlinear pedagogy in physical education. Review of Educational Research, 77(3), 251-278. doi:10.3102/003465430305615

Chow, J., Davids, K., Button, C., Renshaw, I. (2016). Nonlinear pedagogy in skill acquisition. London: Routledge, https://doi.org/10.4324/9781315813042

Chow, J., (2013) Nonlinear Learning Underpinning Pedagogy: Evidence, Challenges, and Implications, Quest, 65:4, 469-484, DOI:10.1080/00336297.2013.807746

Cordovil, R., Araujo, D., Davids, K., Gouveia, L., Barreiros, J., Fernandes, O., \& Serpa, S. (2009). The influence of instructions and body-scaling as constraints on decisionmaking processes in team sports. European Journal of Sport Science, 9(3), 169-179.

Correia, V., Araujo, D., Duarte, R., Travassos, B., Passos, P., \& Davids, K. (2012). Changes in practice task constraints shape decision-making behaviours of team games players. Journal of Science and Medicine in Sport, 15(3), 244-249. doi:10.1016/j.jsams.2011.10.004

Davids, K. (2008). Dynamics of skill acquisition: A constraints-led approach / Keith Davids, Chris Button, Simon Bennett. Champaign, IL: Human Kinetics.

Dicks, M., Davids, K., \& Button, C. (2009). Representative task designs for the study of perception and action in sport. International Journal of Sport Psychology, 40(4), 506524.

Duarte, R., Araujo, D., Correia, V., \& Davids, K. (2012). Sports teams as superorganisms: Implications of sociobiological models of behaviour for research and practice in team sports performance analysis, Sports Medicine, 42 (8): 633-642, DOI: 0112$1642 / 12 / 0008-0633 / \$ 49.95 / 0$

Duarte, R., Araujo, D., Freire, L., Folgado, H., Fernandes, O., \& Davids, K. (2012). Intraand inter-group coordination patterns reveal collective behaviors of football players 
near the scoring zone. Human Movement Science, 31(6), 1639-1651.

doi:10.1016/j.humov.2012.03.001

Esteves, P. T., Araújo, D., Davids, K., Vilar, L., Travassos, B., \& Esteves, C. (2012).

Interpersonal dynamics and relative positioning to scoring target of performers in 1 vs. 1 sub-phases of team sports. Journal of Sports Sciences, 30(12), 1285-1293. doi:10.1080/02640414.2012.707327

Evans, D. J., Whipp, P., \& Lay, B. S. (2012). Knowledge representation and pattern recognition skills of elite adult and youth soccer players. International Journal of Performance Analysis in Sport, 12(1), 208-221.

Fajen, B.R., Riley, M.A., \& Turvey. M, T. (2008). Information, affordances, and the control of action in sport, International Journal of Sport Psychology, (40): 79-107.

Farrow, D., \& Reid, M. (2012). The contribution of situational probability information to anticipatory skill. Journal of Science and Medicine in Sport, 15(4), 368-373. doi:https://doi.org/10.1016/j.jsams.2011.12.007

Furley, A., \& Memmert. D. (2007). "I spy with my little eye!": Breadth of attention, inattentional blindness, and tactical decision making in team sports. Journal of Sport \& Exercise Psychology, 29, S162-S162.

Gibbs, R. W., Jr. (2006). Embodiment and cognitive science. Cambridge University Press. Gibson, J. (1979). The ecological approach to visual perception. Boston: Houghton Mifflin.

Greenwood, D., Davids, K., \& Renshaw, I. (2016). The role of a vertical reference point in changing gait regulation in cricket run-ups. European Journal of Sport Science, 16(7), 794-800. doi:10.1080/17461391.2016.1151943

Gréhaigne, J.-F., Godbout, P., \& Bouthier, D. (1999). The foundations of tactics and strategy in team sports. Journal of Teaching in Physical Education, 18(2), 159-174. 
Hoffman, R. R., Ward, P., Feltovich, P. J., DiBello, L., Fiore, S. M., \& Andrews, D. H. (2014). Accelerated expertise: Training for high proficiency in a complex world. New York: Psychology.

Jackson, R., Warren, S., \& Abernethy, B. (2006). Anticipation skill and susceptibility to deceptive movement, Acta Psychologica, 123(3), 355-371, DOI: https://doi.org/10.1016/j.actpsy.2006.02.002

Johnston, D., \& Morrison, B. W. (2016). The application of naturalistic decision-making techniques to explore cue use in Rugby League playmakers. Journal of Cognitive Engineering and Decision Making, 10(4), 391-410. doi:10.1177/1555343416662181

Kahneman, D., Slovic, P., \& Tversky, A. (1982). Judgment under uncertainty: Heuristics and biases. Cambridge: Cambridge University Press

Kelso, J. A. S. (1995). Dynamic patterns: The self-organization of brain and behavior. The MIT Press.

Klein, G. A., Calderwood, R., \& Clinton-Cirocco, A. (1986). Rapid Decision Making on the Fire Ground. Proceedings of the Human Factors Society Annual Meeting, 30(6), 576580. https://doi.org/10.1177/154193128603000616

Klein, G., Calderwood, R., \& Clinton-Cirocco, A. (2010). Rapid decision making on the fire ground: The original study plus a postscript. Journal of Cognitive Engineering and Decision Making, 4(3), 186-209. https://doi.org/10.1518/155534310X12844000801203

Lex, H., Essig, K., Knoblauch, A., \& Schack, T. (2015). Cognitive representations and cognitive processing of team-specific tactics in soccer. Plos One, 10(2). doi:10.1371/journal.pone.0118219 
Loffing, F., \& Hagemann, N. (2014). Skill differences in visual anticipation of type of throw in team-handball penalties. Psychology of Sport and Exercise, 15(3), 260-267. doi:https://doi.org/10.1016/j.psychsport.2014.01.006

Lorains, M., Ball, K., \& MacMahon, C. (2013). An above real time training intervention for sport decision making. Psychology of Sport \& Exercise, 14(5), 670-674.

Lorains, M., Ball, K., \& MacMahon, C. (2013). Expertise differences in a video decisionmaking task: Speed influences on performance. Psychology of Sport and Exercise, 14(2), 293-297. doi:https://doi.org/10.1016/j.psychsport.2012.11.004

MacMahon, C., \& McPherson, S. L. (2009). Knowledge base as a mechanism for perceptualcognitive tasks: Skill is in the details! International Journal of Sport Psychology, 40(4), 565-579.

MacMahon, C., \& McPherson, S. L. (2009). Knowledge base as a mechanism for perceptualcognitive tasks: skill is in the details! International Journal of Sport Psychology, $40(4), 565-579$.

MacNamara, Á., \& Collins, D. (2015). Twitterati and Paperati: Evidence versus popular opinion in science communication. British Journal of Sports Medicine, 49(19), 1227 1228. doi:10.1136/bjsports-2015-094884\%J

Macquet, A. C. (2009). Recognition within the decision-making process: A case study of expert volleyball players. Journal of Applied Sport Psychology, 21(1), 64-79.

Macquet, A., Kragba, K. What makes basketball players continue with the planned play or change it? A case study of the relationships between sense-making and decisionmaking. Cogn Tech Work, 17, 345-353 (2015). https://doi.org/10.1007/s10111-0150332-4

Mallett, C. J., \& Lara-Bercial, S. (2016). Chapter 14 - Serial Winning Coaches: People, Vision, and Environment. In M. Raab, P. Wylleman, R. Seiler, A.-M. Elbe, \& A. 
Hatzigeorgiadis (Eds.), Sport and Exercise Psychology Research (pp. 289-322). San Diego: Academic.

McPherson, S. L., \& Vickers, J. N. (2004). Cognitive control in motor expertise. International Journal of Sport and Exercise Psychology, 2(3), 274-300. doi:10.1080/1612197X.2004.9671746

McRobert, A. P., Ward, P., Eccles, D. W., \& Williams, A. M. (2011). The effect of manipulating context-specific information on perceptual-cognitive processes during a simulated anticipation task. British Journal of Psychology, 102(3), 519-534. doi:10.1111/j.2044-8295.2010.02013.x

Memmert, D., \& Furley, P. (2007). "I spy with my little eye"! Breadth of attention, inattentional blindness, and tactical decision making in team sports. Journal of Sport \& Exercise Psychology, 29(3), 365-381.

Memmert, D., Baker, J., \& Bertsch, C. (2010). Play and practice in the development of sportspecific creativity in team ball sports. High Ability Studies, 21(1), 3-18. doi:10.1080/13598139.2010.488083

Müller, S., Abernethy, B., \& Farrow, D. (2006). How do world-class cricket batsmen anticipate a bowler's intention? Quarterly Journal of Experimental Psychology, 59(12), 2162-2186. doi:10.1080/02643290600576595

Passos, P., Araújo, D., Davids, K., \& Shuttleworth, R. (2008). Manipulating constraints to train decision making in Rugby Union. International Journal of Sports Science \& Coaching, 3(1), 125-140.

Passos, P., Cordovil, R., Fernandes, O., \& Barreiros, J. (2012a). Perceiving affordances in rugby union. Journal of Sports Sciences, 30(11), 1175-1182. doi:10.1080/02640414.2012.695082 
Paterson, G., van der Kamp, J., Bressan, E., \& Savelsbergh, G. (2013). The effects of perception-action coupling on perceptual decision-making in a self-paced far aiming task. International Journal of Sport Psychology, 44(3), 179-196. doi:10.7352/ijsp2013.44.179

Poplu, G., Ripoll, H., Mavromatis, S. \& Baratgin, J., (2008) How Do Expert Soccer Players Encode Visual Information to Make Decisions in Simulated Game Situations?, Research Quarterly for Exercise and Sport, 79(3), 392-398, doi/abs/10.1080/02701367.2008.10599503

Popper, K. R. (1968). The logic of scientific discovery: [ $3^{\text {rd }}$ ed. (revised)]. London : Hutchinson.

Raab, M., \& Araújo, D. (2019). Embodied cognition with and without mental representations: The case of embodied choices in sports. Frontiers in Psychology, 10(1825). doi:10.3389/fpsyg.2019.01825

Raab, M., Bar-Eli, M., Plessner, H., \& Araújo, D. (2019). The past, present and future of research on judgment and decision making in sport. Psychology of Sport and Exercise, 42, 25-32. doi:https://doi.org/10.1016/j.psychsport.2018.10.004

Ribeiro, J., Davids, K., Araújo, D., Guilherme, J., Silva, P., \& Garganta, J. (2019). Exploiting bi-directional self-organizing tendencies in team sports: The role of the game model and tactical principles of play. Frontiers in Psychology, 10(2213).

Richards, P., Collins, D., \& Mascarenhas, D. (2017). Developing team decision-making: a holistic framework integrating both on-field and off-field pedagogical coaching process. Sport Coaching review, 6(1), 57-75, https://doi.org/10.1080/21640629.2016.1200819

Richards, P., Collins, D., \& Mascarenhas, D. R. D. (2012). Developing rapid high-pressure team decision-making skills. The integration of slow deliberate reflective learning 
within the competitive performance environment: A case study of elite netball. Reflective Practice, 13(3), 407-424. doi:10.1080/14623943.2012.670111

Richards, P., Mascarenhas, D. R. D., \& Collins, D. (2009). Implementing reflective practice approaches with elite team athletes: parameters of success. Reflective Practice, 10(3), 353-363. doi:10.1080/14623940903034721

Roca, A., Ford, P. R., McRobert, A. P., \& Williams, A. M. (2011). Identifying the processes underpinning anticipation and decision-making in a dynamic time-constrained task. Cognitive Processing, 12(3), 301-310. doi:10.1007/s10339-011-0392-1

Roca, A., Ford, P. R., McRobert, A. P., \& Williams, A. M. (2013). Perceptual-cognitive skills and their interaction as a function of task constraints in soccer. Journal of Sport \& Exercise Psychology, 35(2), 144-155.

Roca, A., Williams, A. M., \& Ford, P. R. (2012). Developmental activities and the acquisition of superior anticipation and decision making in soccer players. Journal of Sports Sciences, 30(15), 1643-1652. doi:10.1080/02640414.2012.701761.

Ruano, M., Battaglia, O., Lorenzo Calvo, A., Calvo, J., Saiz, S., \& Sampaio, J. (2015). Effectivenesss during ball screens in elite basketball games, Journal of Sports Sciences, 33(17), 1844-1852, DOI:10.1080/02640414.2015.1014829.

Silva, P., Garganta, J., Araujo, D., Davids, K., \& Aguiar, P. (2013). Shared knowledge or shared affordances? Insights from an ecological dynamics approach to team coordination in sports. Sports Medicine, 43(9), 765-72. doi: 10.1007/s40279-0130070-9.

Simon, H. A. (1956). Rational choice and the structure of environments. Psychological Review, 63, 129-138. 
Steiner, S., Macquet, A.-C., \& Seiler, R. (2017). An integrative perspective on interpersonal coordination in interactive team sports. Frontiers in Psychology, 8(1440). doi:10.3389/fpsyg.2017.01440

Suits, B. (1978). The Grasshopper: Games, Life, and Utopia. Toronto: University of Toronto Press.

Tenenbaum, G., \& Summers, J. (1997). Perception-action relationships in strategic-type settings: Covert and overt processes. Journal of Sports Sciences, 15(6), 559-572. doi:10.1080/026404197366994

Tenenbaum, G., Levy-Kolker, N., Sade, S., Liebermann, D. G., \& Lidor, R. (1996). Anticipation and confidence of decisions related to skilled performance. International Journal of Sport Psychology, 27(3), 293-307.

Toner, J., \& Moran, A. (2015). Enhancing performance proficiency at the expert level: Considering the role of 'somaesthetic awareness'. Psychology of Sport and Exercise, 16, 110-117. doi:https://doi.org/10.1016/j.psychsport.2014.07.006

Toner, J., Montero, B. G., \& Moran, A. (2015). The perils of automaticity. Review of General Psychology, 19(4), 431-442. doi:10.1037/gpr0000054

Travassos, B., Araujo, D., Davids, K., Esteves, P. T., \& Fernandes, O. (2012). Improving passing actions in team sports by developing interpersonal interactions between players. International Journal of Sports Science \& Coaching, 7(4), 677-688. doi:10.1260/1747-9541.7.4.677

Van den Berg, P., \& Malan, D. D. J. (2012). The effect of Experimental Law Variations on the Super 14 Rugby Union Tournaments. African Journal for Physical Activity and Health Sciences, 18(3), 476-486.

Veronesi, C. (2014). Falsifications and scientific progress: Popper as sceptical optimist. Lettera Matematica, 1(4), 179-184. doi:10.1007/s40329-014-0031-7 
Warren, W. H. (2006). The dynamics of perception and action. Psychological Review, $113(2), 358-389$.

Williams, A.M., \& Davids, K. (1998). Visual search strategy, selective attention, and expertise in soccer. Research Quarterly for Exercise and Sport, 69(2), 111-128. doi:10.1080/02701367.1998.10607677

Williams, A. M., \& Jackson, R. C. (2019). Anticipation in sport: Fifty years on, what have we learned and what research still needs to be undertaken? Psychology of Sport and Exercise, 42, 16-24. doi:https://doi.org/10.1016/j.psychsport.2018.11.014

Williams, A. M., \& Jackson, R. C. (2019). Anticipation in sport: Fifty years on, what have we learned and what research still needs to be undertaken? Psychology of Sport and Exercise, 42, 16-24. doi:https://doi.org/10.1016/j.psychsport.2018.11.014

Williams, A. M., \& Ward, P. (2007). Anticipation and decision making: Exploring new horizons. In G. Tenenbaum \& R. C. Eklund (Eds.), Handbook of sport psychology (pp. 203-223). New York: John Wiley \& Sons.

Williams, A.M., \& Ward, P. (2007). Perceptual-cognitive expertise in sport: Exploring new horizons. In G. Tenenbaum \& E. Eklund, L. (Eds.), Handbook of Sport Psychology (pp. 203-223). New York: John Wiley \& Sons.

Wilson, R., Dicks, M., Milligan, G., Poolton, J., \& Alder, D. (2018). An examination of action capabilities and movement time during a soccer anticipation task. Movement in Sport Sciences, 102, 61-70, https://doi.org/10.1051/sm/2019001

Witt, J.K., Riley, M.A. (2014). Discovering your inner Gibson: Reconciling action-specific and ecological approaches to perception-action. Psychon Bull Rev, 21, 1353-1370. https://doi.org/10.3758/s13423-014-0623-4

Zsambok, C. E., \& Klein, G. (Eds.). (1997). Expertise: Research and applications. Naturalistic decision making. Lawrence Erlbaum Associates, Inc. 